\title{
ACQUIRING AND EXTRACTION OF INFORMATION COLLECTED BY UNMANNED AERIAL VEHICLES AND OMNIDIRECTIONAL CAMERAS AND THEIR APPLICATIONS THROUGH MANAGEMENT SOFTWARE
}

\author{
Marcelo de Abreu \\ TECSYSTEM Tecnologia em Software, Castelo/ES - Brazil - marcelo@ tecsystem.com.br
}

KEYWORDS: UAV, aerial survey, omnidirectional cameras, management software, public administration, GIS, mobile mapping

\begin{abstract}
:
The growth of technology for aerial and land mapping, as well as information management, has made great progress over the past decade. When we talk about public administration, we envision a sector lacking the use of these new features, as it has been using old models of data acquisition and information management, however slowly opening their eyes to this inevitable advance.

Unmanned Aerial Vehicles (UAVs), $360^{\circ}$ mapping and Management Software, integrated with a Geographic Information System (GIS), are the latest trend in city management. These features offer quality, agility and reliability, generating an increase in the municipality's total revenue, along with reducing costs throughout the registration and control process.

The objective of this paper is to demonstrate the methodologies applied in the phases of air and ground data acquisition, their processing and generated products, the collection of information from city halls and the import of existing data into Tecsystem's management software, as well as the different applications of the information in various secretariats of the public municipal administration.
\end{abstract}

\section{INTRODUCTION}

The world population in 1950 was 2.5 billion people. By 2000 this number was already more than 6 billion humans on the planet $^{1}$ and according to the UN report ${ }^{2}$, by 2050 the world population will be 9.7 billion, most of which will be concentrated in cities. In Brazil, $84 \%$ of the population live in urban areas and only $16 \%$ live in rural areas.

During these last 70 years cities have been growing at a pace never seen before. The population has migrated to urban centers in a fast and disorderly manner, causing serious problems in territorial use and occupation. Because of this chaotic growth, most of the information in the municipalities is out of date.

The knowledge on the population's information, as well as its distribution, is of prime importance for the public administration, causing direct impacts on revenues and expenses, influencing the decisions to be taken.

One of the best ways to get information about a city is to know how its territory is divided, together with the multi-purpose registry.

In order to achieve this goal, some solutions have been standing out and ensuring high performance in this process. The use of Unmanned Aerial Vehicles (UAVs) to perform aerial surveys, for example, has been configured as one of the most innovative tools to assist in acquiring city data.

The spatial and temporal resolutions, operational facilities, costs and time to obtain urban geoinformation resulting from UAV surveys stand out when compared to conventional aerial

${ }^{1}$ https://pt.wikipedia.org/wiki/Crescimento_populacional

${ }^{2} \mathrm{https} / / /$ nacoesunidas.org/populacao-mundial-deve-chegar-a-97-bilhoesde-pessoas-em-2050-diz-relatorio-da-onu/ surveys. Another important factor is that manned aircraft have operational limiters, hampering its use to map small areas.

Orbital images and those taken with manned aircraft continue and will continue to be used in urban mapping, however, in certain applications that require higher resolution, shorter product acquisition time and low cost, it is clear that the facilities and automation of existing processes in Photogrammetry performed by the UAV are fundamental in the generation of cartographic products most suitable for city administration.

The $360^{\circ}$ terrestrial mapping has also been highlighted the cities, since the georeferenced multidirectional image generated by the system provides additional information in the registration of properties, as well as can be used to check the conditions of the pavement of roads, location and classification of vegetation, location of fire hydrants, poles, culverts, state of aerial wiring or any other information regarding the visible aspect.

The tools mentioned above are information generators, requiring a high degree of organization, classification and filtering. The management software appears as a fundamental part in this process, integrating the information existing in the municipal governments database and the information generated by the aerial survey and the $360^{\circ}$ terrestrial mapping, in addition to acting as an interface for the end user, who will insert new data and retrieve compiled information.

These information, albeit numerous and complex, when entered and processed by the Tecsystem Management System, is presented in a simple and intuitive way through graphs, reports and maps, allowing its analysis and use by operators who are not necessarily technical or technical specialists in Geographic Information System (GIS), thus facilitating the dissemination of these information and supporting decisions to be made by public servants and managers. 
As already mentioned, the methodology to be used to acquire urban geoinformation is one of the most important steps for the implementation of a GIS integrated management software in urban administration. In this sense, this article presents the main steps employed by the company Tecsystem for the acquisition of urban information, using aerial images originated from UAV, integrated with $360^{\circ}$ terrestrial survey.

\section{DATA COLLECTION METHODOLOGY}

With the objective of creating the Multipurpose Technical Registry $^{3}$ and the knowledge on the territorial use and occupation in the municipality's urban area, a work plan should be elaborated for the collection of primary data, which are composed by UAV aerial images, $360^{\circ}$ images and current information existing in the municipal registry.

This plan should be broken down into 3 steps, which can be executed simultaneously:

- Step 1: Generation of the aerial survey images performed by the UAV, along with the resulting products.

- Step 2: Generation of $360^{\circ}$ mapping images performed by the mobile land mapping unit, along with the resulting products.

- $\quad$ Step 3: Survey the pre-existing information with the City Hall in order to compile this data for use in the software.

\subsection{Step 1 - Air and Image Processing}

To perform the aerial survey flight, the polygon of the urbanized area to be mapped must be defined, with special attention to the topography of the land inside and on the edges of this polygon.

Using flight planning software, the takeoff and landing locations as well as the flight lines that the aircraft will fly in must be defined, always taking into account the geomorphology of the municipality's urban perimeter and the parameters to generate a frontal overlap of the $80 \%$ photos and $70 \%$ lateral overlap, along with the flight height as a function of the desired Ground Sample Distance (GSD) for the project.

It is recommended to set the flight height to generate a GSD no higher than $5 \mathrm{~cm} /$ pixel, offering a high-resolution image.

The suggested maximum flight height in urban areas varies depending on the equipment, sensor, and permits that the aerial survey company is granted to. But it is important that during the work, the aircraft follows the natural unevenness of the terrain, thus generating an equal GSD value for the entire mapped area.

Images should be captured between 10 am and 3 pm local time, with adequate cloud cover conditions, in order to avoid low illumination and excessive shadow projection.

\footnotetext{
${ }^{3}$ The Multipurpose Technical Registry can be understood as a system of registration of the spatial elements that represent the urban structure, consisting of a geometric and a descriptive component that provides agility and diversity in collecting data to meet different functions, including urban planning (BLACHUT et al, 1974).
}

Aiming to conduct the flight in the best possible weather conditions, it is advisable to follow the weather forecasts of the region to be imaged for a period of two weeks prior to the execution of the project, thus anticipating any climate change that may hinder the smooth progress of the job.

To assist in the final result of the aerial survey, land support points are determined using a geodetic GPS receiver. These points can be natural elements or artificial targets, inserted before flight, in order to verify the accuracy and precision of the aerial mapping. It is also advisable to use the Fundamental Geodetic Support Network of the Brazilian Institute of Geography and Statistics (IBGE, 2019), if available in the region.

Taking into account the full legality of carrying out an aerial survey work in Brazil, it is necessary that the performing aerial survey company must be registered in category " $A$ " with the Ministry of Defense (MD, 2019), since every aerial survey service in Brazil is controlled by this body. Also, it must apply for the permits listed below:

- Authorization with the MD for the aerial survey project;

- Authorization by the Department of Airspace Control (DECEA, 2019) to enter Brazilian airspace.

The following documents are also required for the flight:

- UAV registration certificate, issued by the National Civil Aviation Agency (ANAC, 2019);

- UAV homologation certificate issued by the National Telecommunications Agency (ANATEL, 2019);

- insurance against damage to third parties in unmanned aircraft operations;

- aircraft manual;

- Preparation and use of an operational risk assessment for unmanned aircraft operators that meets the requirements of paragraphs E94.103(f)(2) and E94.103(g)(2) of RBAC-E No. 94.

With a view to ensuring the safety of the operation, people and property located below the flight area, which, as it is urbanized, is densely populated, it is highly recommended that the equipment used for this purpose should have an emergency system equipped with a parachute.

Similarly, it is advisable that the Unmanned Aircraft System operator be a trained pilot and certified for such an operation.

In the work performed by Tecsystem, a fixed wing UAV equipped with emergency parachute, RTK L1/L2 system, high precision inertial system and 24MP Sony ILCE-5100 RGB type embedded camera is also used. The System operator is trained and has all the necessary certifications.

Once the aerial image collection has been completed, the processing of this material should be started, which can be performed by various commercially available software. But it is essentially important to be aware of the features and results generated by each of these applications.

Another sensitive point in this process is the processing capacity of the computers used, since the amount of images generated varies depending on the size of the flyover area. 
In the work performed by Tecsystem, Agisoft Metashape Professional and Pix4Dmapper image processing software are used, along with high-processing computers.

By using Real Time Kinematic (RTK) technology in line with the inertial system embedded in the aircraft, a 2 -cm planimetric and $3-\mathrm{cm}$ altimetric accuracy has been achieved without the use of processing control points when considering flights with $3-\mathrm{cm}$ GSD.

Therefore, the support points collected only for the purpose of checking the accuracy and precision of the model are inserted.

As a result the following products are obtained from the aerial survey:

- Conventional orthophoto: photographic representation in orthogonal projection of a region of the earth's surface, in which all ground-level cartographic entities have the same scale, free of errors and deformations, with the same validity as a cartographic plane.

- Digital Surface Model (MDS): set of points with known coordinates in a given cartographic reference system, equidistant or not and with known elevation.

- Level curve: imaginary line that joins all points of equal altitude of a represented region. It is called a "curve" because usually the line that results from studying the altitudes of a terrain is usually manifested by curves.

These products must comply with the decree 89.817 of June 20, 1984, which establishes the Regulatory Instructions of the Brazilian Technical Standards of Cartography, through procedures and standards to be followed in the preparation and presentation of cartographic documents in the Brazilian territory.

\subsection{Step 2 - 360 ${ }^{\circ}$ Mapping Phase and Image Processing}

To perform the $360^{\circ}$ mapping all urban land roads accessible and covered by the aerial survey must be defined.

As shown in Figure 1, the service is performed by a mobile land mapping unit that runs through all urban roads of the municipality. This unit carries a georeferenced multidirectional terrestrial image generator system.

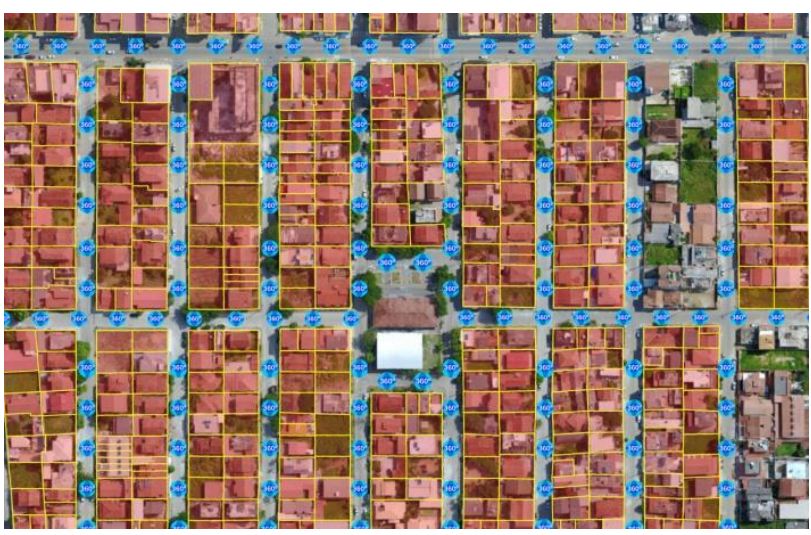

Figure $1.360^{\circ}$ images
The system captures $360^{\circ}$ images every $10 \mathrm{~m}$ of displacement. This ensures broad coverage of all points of interest for registration. As an example, we can cite:

- building facades;

- condition of the roads;

- sidewalks;

- vertical and horizontal signs;

- traffic lights;

- trees;

- drainage system;

- poles.

All items of interest of the municipal administration and viewable can be registered.

An important point to mention is that the height of the images taken by the system must be at least 3 meters above ground level. This height is justified by the need to collect the facade of buildings for real estate registration. To achieve this end, the camera must be above the height of the walls.

The images taken very close should be selected, as it was caused by the mobile unit passing several times in the same street during the survey, as well as they should be sorted by street designation. After this selection, processing is started for the purpose of correcting brightness and contrast.

\subsection{Step 3 - Pre-existing Information Gathering}

To carry out this part of the process, a team responsible for compiling pre-existing information in the municipality should collect from the secretariats the following materials:

- existing mappings, both in digital and analogical media;

- cartographic bases;

- real estate registration database (which contains information regarding people and their respective properties, public places and spatial divisions);

- copy of current municipal master plan;

- copy of current municipal tax code;

- other necessary information.

All data provided by the municipality must go through an analysis and compilation, where errors, inconsistencies and incompatibility of information will be verified, through in-depth research in the competent bodies such as the Brazilian Institute of Geography and Statistics (IBGE, 2019).

\section{DATA INTEGRATION IN MANAGEMENT SOFTWARE}

With the completion of the steps described above, the process of inserting the aerial survey data, $360^{\circ}$ mapping and pre-existing information into the management software begins, which enables the integration of all collection stages.

As can be seen in the Figure 2, the orthophoto, along with $360^{\circ}$ images, provides an overview of the property, being possible to view the same building vertically (top view image) and horizontal (front view image). Thus one can obtain a measurement of the lots and buildings, as well as the visualization of the façades, allowing an update of the technical 
register of the real estate, dispensing the visit in loco by the City Hall inspectors, in the majority of the lots and constructions.

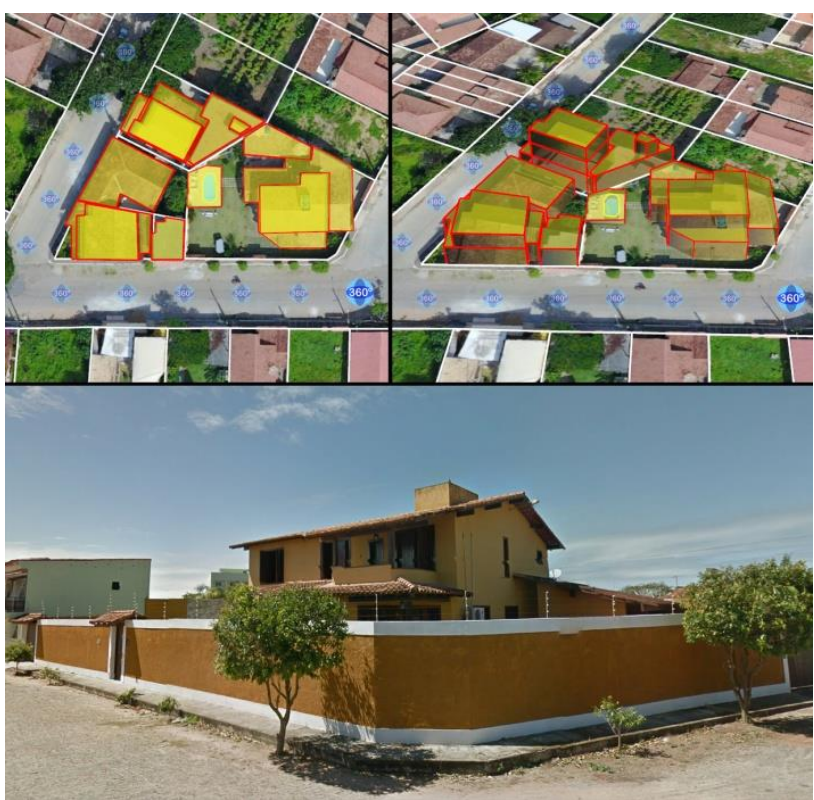

Figure 2. Orthophoto and $360^{\circ}$ image

In the same way, as can be seen in Figures 2 and 3, the blocks, the neighborhoods, the industrial sectors, the risk areas, the environmental preservation areas, the municipal master plan and any other relevant polygons can be vectorized, allowing a good spatial division of the urban area. Thus becoming visually and geographically known and delimited the use and occupation of the territory in the urban area of the municipality.

By linking the images with the pre-existing information in the city hall, the database is being completed, creating a structure that can serve several departments and sectors, since the more data are stored in the register, the more useful the information becomes.

This integration is an important process, as from it one can see via software, in an organized, classified and filtered way, information that was once only viewed in isolation.

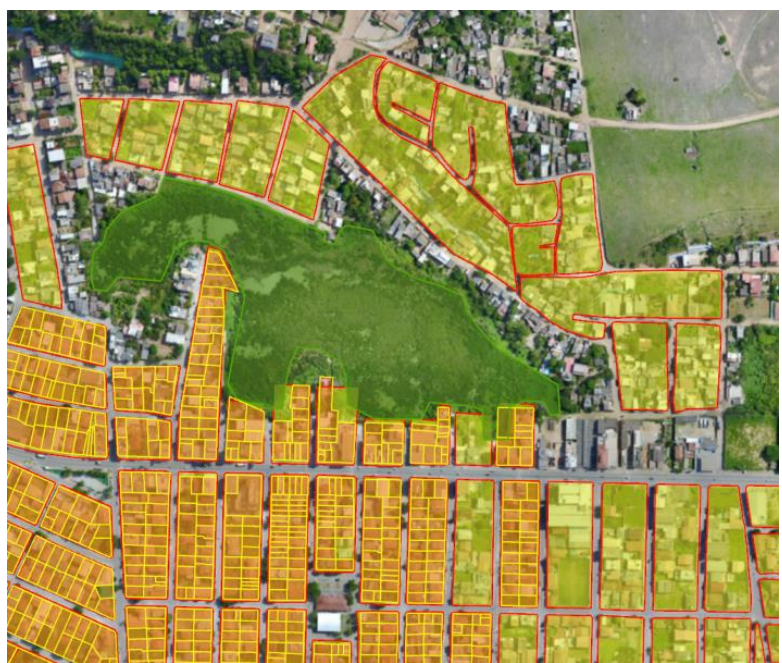

Figure 3. Blocks and lots
During this process, it is important to train and empower the City Hall staff, so that they can vectorize the properties and feed the software with new data, since it is always necessary to add new information or change existing ones. This is a constant process in any public administration body.

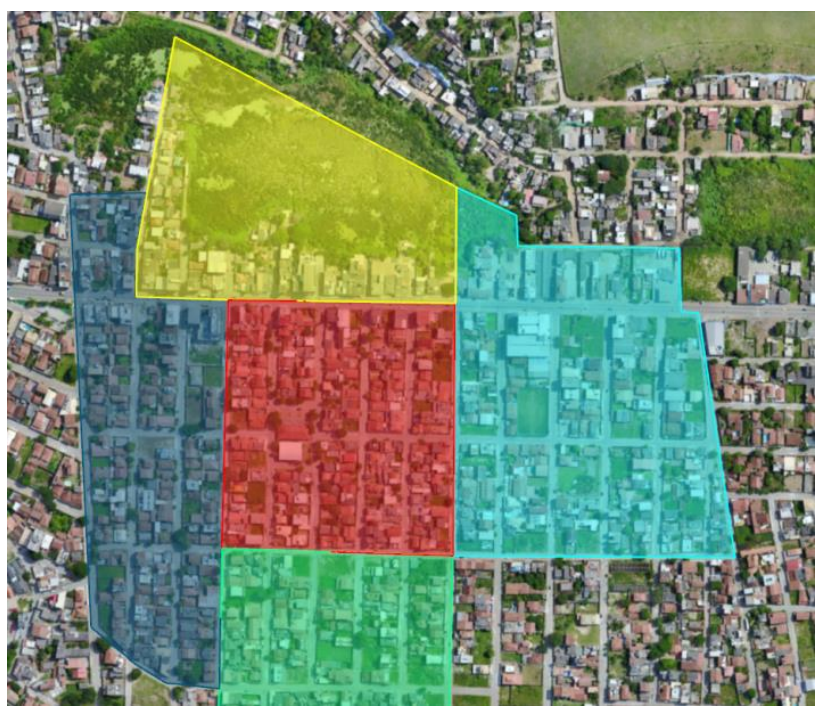

Figure 4. Neighborhoods

\section{DISCUSSIONS AND CONCLUSIONS}

In all the ongoing or already implemented deployments it was found that in the first moment there was a considerable increase in the municipality tax collection, accounted for the increase in the number of properties registered and the increase in the venal value of each building, consequently increasing the value of the property tax, providing conditions for new investments in health, education, social assistance, infrastructure, among others. This result in all observed cases was much higher than the project implementation value.

Secondly, with the participation of various secretariats using the system, it is clear the facilities generated in serving the citizen, bringing agility, reliability and cost reduction in routine tasks.

This communication between the secretariats is only possible due to the networking model of Tecsystem management software, creating a new standard in the way information is exchanged, since in the models used so far, there is no interaction, remaining each sector isolated as an island.

Several departments and agencies (health, social action, transportation, planning, public safety, environment, civil defense, land regularization, among others) feed the system with information that is used by all, facilitating the dissemination of data and making that all parties involved work in synergy.

With this possibility of shared information management through the management software, each independent user of the sector to which he/she is linked becomes a GIS user, feeding and removing information from the system.

Information that previously was not viewable, either because it was missing or not integrated with other data, is now 
categorized and filtered in the system and can be displayed in spreadsheets, reports, charts and even GIS platforms. In this way, the improvement of all public management processes is verified.

Another major change is in the way the information of the surveys performed are processed within the municipalities. In previous models, there is a need for a GIS department, with specific professionals to handle, generate products and meet requests from other sectors, concentrating knowledge on a few servers and overloading them.

All of the above benefits are possible when three technologies are used in synergy:

1. UAVs to carry out aerial surveys, generating high quality products that will serve as a basis for making the features of buildings, plots, blocks, neighborhoods, sectors and important polygons.

2. $360^{\circ}$ images assisting in the registration update and knowledge of the various points of interest of the administration, which working together with the aerial images, will allow a total visualization of any point of interest.

3. management software to gather all pre-existing and collected information, as well as to enable the insertion of new data, acting as an information center.

With the geographical visual knowledge of the city it is possible to meet the objectives of the Municipal Master Plan, which aims to establish criteria for urban territorial occupation and use, with a view to fulfilling the social function of property, as well as planning growth, aiming to minimize the impacts on fragile environmental areas.

Finally, the primary objective of supporting city management decision-making can be achieved, as legal officials have immediate access to all the information gathered in Tecsystem's management software.

\section{ACKNOWLEDGEMENTS}

I thank Tecsystem for the financial, logistical and technical support.

To Professor Edson Aparecido Mitishita, for guidance, trust and friendship.

\section{REFERENCES}

ANAC - National Civil Aviation Agency. anac.gov.br/assuntos/paginas-tematicas/Drones (29 november 2019).

ANATEL - National Telecommunications Agency. anatel.gov.br/institucional/component/content/article?id=1485

(29 november 2019).

DECEA - Department of Airspace Control. decea.gov.br/drone (29 november 2019).

BLACHUT, T. et al. Cadastre as a basis of a general land inventory of the country. In: Cadastre: various functions characteristics techniques and the planning of land record system. Canada: National Council, 1974.

IBGE - Brazilian Institute of Geography and Statistics, 2019. ibge.gov.br/geociencias/informacoes-sobre-posicionamentogeodesico/rede-geodesica (29 november 2019).

MD - Ministry of Defense, defesa.gov.br/aerolevantamento (29 november 2019). 